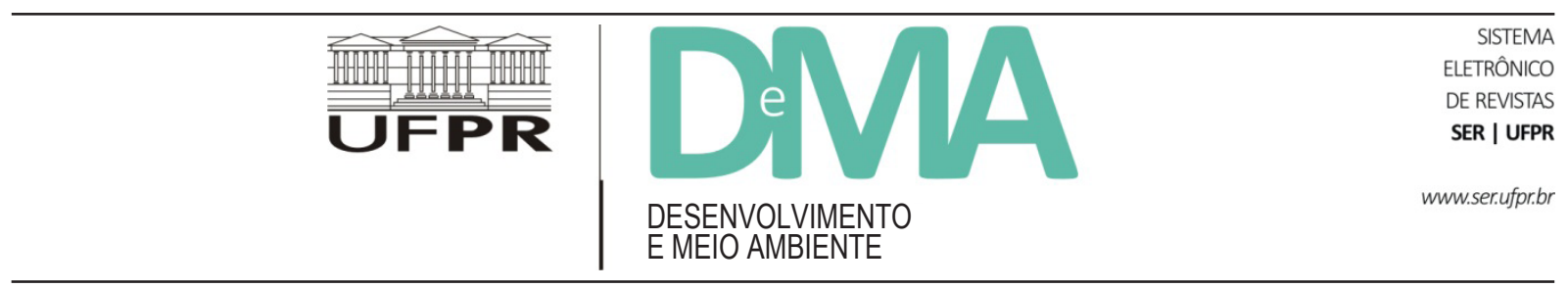

\title{
Editorial
}

\section{Homenagem a Magda Zanoni}

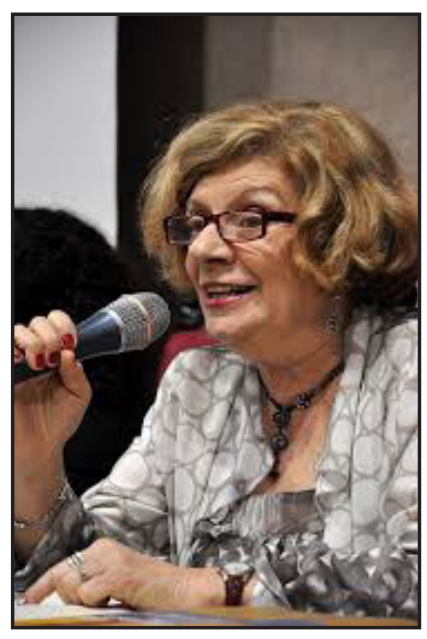

Este editorial se inicia com a fotografia de Magda Zanoni e foi escrito com a tristeza de anunciar seu falecimento no dia 10 de março, em Paris, França. Os editores da Desenvolvimento e Meio Ambiente foram seus colegas e amigos, alguns seus alunos também: acompanharam-na em muitas de suas ousadias intelectuais, científicas e políticas. Viram-na plena de vida e energia, com seu desejo incessante de fazer uma diferença no mundo. Para lutar pelos seus ideais, ela nos ensinava a compartilhá-los, nos empurrava, se necessário, com sua força. Durante sua trajetória, tocou a vida de inúmeras pessoas no Brasil e na França, fez história no seu país de origem e no seu país de adoção.

Magda Zanoni foi a principal co-fundadora do Doutorado em Meio Ambiente e Desenvolvimento da Universidade Federal do Paraná (1993) e fundadora, com Claude Raynaut, dos Cadernos em Desenvolvimento e Meio Ambiente (1994), publicação precursora da nossa revista.

Graduada em Ciências Naturais e Ciências Biológicas e Geológicas pela Universidade Federal do Rio Grande do Sul (UFRGS), complementou seus estudos na França, onde cursou a Maîtrise d'Écologie na Universidade de Paris Sud-Orsay (1969), a Maîtrise d'Etude du Milieu, na Universidade Paris VII (1974) e obteve o Diplome d'Etudes Approfondies, da Escola de Altos Estudos em Ciências Sociais, opção Ecodesenvolvimento (1976-77). Em 1983 doutorou-se em Sociologia do Desenvolvimento pela Universidade Paris I - Panthéon-Sorbonne. Foi pesquisadora e professora do Instituto de Geografia, na Universidade Paris VIII, na área de desenvolvimento e meio ambiente (19711987). Em seguida, tornou-se professora e pesquisadora da Universidade Paris VII, na área de Ecologia Geral, Ecologia Aplicada e na Unidade de Formação e Pesquisa de Biologia e Genética (1987-1989). Em 1990, foi aprovada em concurso e nomeada Maître de Conférence na Universidade Paris 7 Denis Diderot, na área de Meio Ambiente, onde se aposentou. Recentemente estava vinculada, como pesquisadora, ao LADYSS - Laboratoire Dynamiques Sociales et Recomposition des Espaces do CNRS (Conseil National de la Recherche Scientifique da França), situado na Universidade de Paris Ouest Nanterre La Defense (antiga Paris 10).

No Brasil, foi professora e pesquisadora do Programa de Pós-Graduação em Meio Ambiente e Desenvolvimento da Universidade Federal do Paraná, onde seu trabalho inestimável foi reconhecido pela outorga do título de Doutor Honoris Causa da UFPR. Foi também professora e pesquisadora do Programa de Pós-Graduação em Desenvolvimento Rural da Univer- 
sidade Federal do Rio Grande do Sul e consultora do Ministério do Desenvolvimento Agrário, no qual foi co-fundadora do Grupo de Estudos sobre Agrobiodiversidade (GEA) que acompanha as reuniões da Comissão Técnica Nacional de Biossegurança (CTNBio) e produz informações sobre temas como agroecologia, agricultura familiar e biossegurança. Publicou artigos e livros sobre estes temas. Destacamos o livro que marcou época na discussão sobre os transgênicos no Brasil: Transgênicos para quem?

Não poderíamos enumerar aqui tudo que Magda legou à França e ao Brasil. Sua carreira científica foi sempre eivada pelas ideias que a levaram a ficar afastada de seu país até a Lei da Anistia, em 1979: lutava pela democracia, pela liberdade, pela justiça social, pelo fim da miséria, pela inclusão social e política dos pobres, dos marginalizados, pela Reforma Agrária. Lutava pela vida, em todos os seus sentidos. Na França ficou sempre com uma parte de sua alma ligada ao Brasil, sem deixar de trabalhar também por tudo que era alternativo na França: sua presença foi marcante entre agricultores franceses ligados à agroecologia e suas associações, nos círculos de defesa do ambiente e nos defensores da Science Citoyenne. Recentemente, trouxe esta concepção para o Brasil e foi a principal articuladora do Movimento Ciência Cidadã, a partir de Manifesto lançado em 2012 no V Encontro da Rede de Estudos Rurais do Brasil (Belém, Pará).

Em 2013, foi homenageada na Semana da Solidariedade Internacional, que ocorreu em Paris, França, com o tema "Direito à Alimentação", onde foi concedido o título de Diplomata Alternativo para personalidades acadêmicas que contribuíram para a pesquisa ligada aos problemas e desafios do desenvolvimento.

Neste momento de sua partida, um informativo francês independente e crítico sobre os transgênicos, biotecnologia e sementes - o Info OGM, veille citoyenne - publicou um número especial com uma homenagem a Magda em que resume a sensação de todos os que a conheceram:

Pesquisadora generosa, militante, cidadã, ela viveu guiada por um sonho: um mundo mais justo, mais respeitoso da vida, mais alegre. Mas ela não sonhou apenas: ela lutou, se mobilizou no Brasil e na Europa [...]. Obrigada, Magda, obrigada.

Ficará sempre entre nós seu exemplo de força e não conformismo.

Apesar de nossa tristeza, somos profundamente reconhecidos pela parte que pudemos compartilhar na sua passagem pela vida.

Como homenagem ao seu papel relevante na construção de nosso Programa de Pós-Graduação, republicamos neste volume, em seção especial, o prefácio dos Cadernos em Desenvolvimento e Meio Ambiente número 1, 1994, e o texto fundador do programa, ambos de Magda Zanoni e Claude Raynaut.

Os Editores

\section{Equipe Editorial e Técnica responsável pelo volume:}

Editores-chefes: Angela Duarte Damasceno Ferreira e José Milton Andriguetto Filho Editores adjuntos: Lucia Helena de Oliveira Cunha, Ricardo Ojima e Thiago Zagonel Serafini

Secretaria científica: Letícia da Costa da Silva, Tiago Mafra e Roberta Giraldi Romano

Pareceristas da revista: ver em $<$ http://ojs.c3sl.ufpr.br/ojs2/index.php/made/about/editorialPolicies\# custom-2> .

Revisão de texto (português): Reinaldo Cezar Lima e Empresa Bobidiomas

Revisão de texto (inglês): Carolina Alves Ferreira e Empresa Bobidiomas

Editoração eletrônica: Reinaldo Cezar Lima

Design: Oscar Reinstein

ISSN: 1518-952X, eISSN: 2176-9109 